\title{
Reference range for serum cortisol in well preterm infants
}

\author{
Matthias Heckmann, Stefan A Wudy, Doris Haack, Frank Pohlandt
}

\begin{abstract}
Aim-To establish a reference range for serum cortisol concentrations in preterm infants with a gestational age of less than 30 weeks during the first two weeks of life. Methods-Infants were prospectively classified by the following exclusion criteria: surfactant administration, arterial hypotension, acute or uncontrolled infection, ventricular haemorrhage II $^{\circ}$ or above, serum glucose $<2.2 \mathrm{mmol} / 1$, exchange transfusion, stress as a result of any kind of examination or nursing for at least 4 hours before blood sampling. The cortisol value was measured once using radioimmunoassay in each infant.

Results-In appropriate for gestational age (AGA) infants $(n=37$, median gestational age 27.7 weeks, median birthweight $1030 \mathrm{~g}$ ) the distribution of the cortisol concentrations was non-Gaussian. These had a nearly normal distribution, when $\log _{10}$ values of the data were used. The points determined by mean ( $2 \mathrm{SD}$ ) on the logarithmic scale were transformed back to the original units to provide a reference range: $73-562 \mathrm{nmol} / 1$. Gestational age was significantly $(p=0.033)$ associated with cortisol values $\left(\log _{10}\right)$ with a regression coefficient (standard error) of $-0.045(0.020)$. Small for gestational age (SGA) infants $(n=8)$ had significantly higher cortisol values (median $357 \mathrm{nmol} / \mathrm{l}$ ) than AGA infants (median $199 \mathrm{nmol} / \mathrm{l}$ ) $(\mathrm{p}=0.028)$.
\end{abstract}

Conclusions-There is a strictly defined reference range of serum cortisol concentrations in AGA preterm infants.

(Arch Dis Child Fetal Neonatal Ed 1999;81:F171-F174)

Division of

Neonatology and

Paediatric Critical

Care

Department of

Paediatrics

University of Ulm

Germany

M Heckmann

S A Wudy

F Pohlandt

Department of

Pharmacology

University of

Heidelberg

Germany

D Haack

Correspondence to: Professor Frank Pohlandt.

Accepted 14 June 1999
Keywords: reference range; serum cortisol; preterm

Critically ill preterm infants may have inadequately low serum cortisol concentrations. ${ }^{1}$ The lowest cortisol values were found in those preterm infants who had the highest ventilatory requirements, had received surfactant, or who had been treated with inotropes. ${ }^{2}$ Arterial hypotension in preterm infants, which might reflect adrenal insufficiency, was successfully treated with dexamethasone or hydrocortisone..$^{3-5}$ So far, reference values for cortisol have not been established in healthy preterm infants with a gestational age of under 30 weeks. This prospective study aimed to measure cortisol in healthy preterm infants during the first two weeks of life.

\section{Methods}

All infants under 30 weeks of gestational age who had been admitted to our newborn intensive care unit were eligible for study. Gestational age was determined using the expanded Ballard score ${ }^{6}$ and/or the date of the mother's last menstrual period. Small for gestational age (SGA) was defined as a birthweight below the 10th percentile. ${ }^{7}$ The infants had no family history of adrenal illnesses, no congenital anomalies, surgery, or postnatal corticosteroid treatment before blood sampling. Prenatal betamethasone treatment, which consisted of two doses (12 mg) betamethasone for a minimum of 24 hours before birth, was not an exclusion criterion. After birth the infants were randomly assigned to one day of blood sampling during the first 14 days. In each infant one sample was drawn between 0400 and 0800 hours by venepuncture or via an indwelling catheter. For the interval 48 hours before to 24 hours after blood sampling the following exclusion criteria were applied: surfactant administration, arterial hypotension, acute or uncontrolled infection, acute or ventricular haemorrhage $\mathrm{II}^{\circ}$ or more ${ }^{8}$ serum glucose $<2.2 \mathrm{mmo} / 1$ (40 mg/dl), exchange transfusion, stress induced by medical measures such as ultrasound scans, $x$-ray picture, blood sampling, intubation or major nursing for at least 4 hours before blood sampling. Arterial hypotension was defined as a mean arterial blood pressure of less than 23-24 mm Hg (birthweight 500-750 g), 25-26 $\mathrm{mm} \mathrm{Hg}$ (750-1000 g), 27-28 mm Hg (1000$1250 \mathrm{~g})$ and $30 \mathrm{~mm} \mathrm{Hg}(1250-2000 \mathrm{~g})$ and the necessity of treatment (volume expansion, catecholamines).

The study was approved by the Ethics Committee of the University of Ulm and written informed consent was obtained from the parents.

Blood samples for cortisol measurement were immediately centrifuged and serum was stored at $-20^{\circ} \mathrm{C}$ until assayed, as described before. ${ }^{9}$ In brief, precipitation of proteins with ethanol was followed by direct radioimmunoassay using a high specific antibody. The intra-assay and interassay variabilities were $4.0 \%$ and $10 \%$, respectively. The limit of detection of the assay calibration curve was 2.5 pg.

All data were analysed using the Statistica (version 5) statistical package (StatSoft, Inc., Tulsa, USA). The Mann-Whitney U test was used for non-parametric comparisons, the $\chi^{2}$ test to analyse differences in proportions, and a multiple regression analysis was done to investigate the effect of gestational age, postnatal 
Table 1 Clinical characteristics of well preterm infants and serum cortisol values

\begin{tabular}{llll}
\hline & $A G A(n=37)$ & $S G A(n=8)$ & $p$ Value \\
\hline Gestational age (weeks) $^{\star}$ & $27.7(24.7-29.9)$ & $27.6(25.6-29.3)$ & $0.95 \dagger$ \\
Birthweight $(\mathrm{g})^{\star}$ & $1030(690-1580)$ & $680(500-895)$ & $0.00012 \dagger$ \\
Sex (females/males) & $20 / 17$ & $8 / 0$ & $0.015 \ddagger$ \\
Apgar scores ${ }^{\star}$ at 5 mins & $8.5(5-10)$ & $9(6-10)$ & $0.72 \dagger$ \\
Apgar scores at 10 mins & $9(7-10)$ & $9(8-10)$ & $0.82 \dagger$ \\
Umbilical cord pH* & $7.30(7.03-7.42)$ & $7.19(6.68-7.36)$ & $0.0089 \dagger$ \\
Prenatal steroids & $31(84 \%)$ & $6(75 \%)$ & $0.75 \ddagger$ \\
Caesarean section & $29(78 \%)$ & $8(100 \%)$ & $0.15 \ddagger$ \\
Cortisol (nmol/1) & $199(58-475)$ & $359(130-519)$ & $0.028 \dagger$ \\
\hline
\end{tabular}

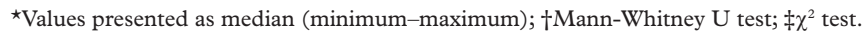

Table 2 Reference range for serum cortisol in well preterm infants

\begin{tabular}{ll}
\hline Gestational age (weeks) & Cortisol (nmolll) \\
\hline 24 & $110-744$ \\
25 & $100-671$ \\
26 & $90-605$ \\
27 & $81-545$ \\
28 & $73-491$ \\
29 & $66-443$
\end{tabular}

Based on the regression equation $(\log ($ cortisol $)=3.5373-$ $0.045 \times \mathrm{GA})$ and the residual standard deviation $(0.207098)$ about the regression line, a reference range for each week of GA is given by the points determined by mean \pm 2 residual standard deviations on the logarithmic scale, which were transformed back to the original units.

age, and birthweight on cortisol values. The level of significance was set at $\mathrm{p}=0.05$.

Results

Between August 1996 and January 1998, 99 infants were enrolled in the study. Forty seven fulfilled our criteria for good health. Table 1 shows the demographic characteristics. Only one infant was being mechanically ventilated at the time of blood sampling. No infant was treated with phenobarbital or phenytoin before or at the time of blood sampling.

Before further analysis of the cortisol pattern two outliers (1233 and $2050 \mathrm{nmol} / \mathrm{l}$ ), both measured on the first day of life, were excluded by visual inspection. ${ }^{10}$ SGA infants had significantly higher cortisol values than appropriate for gestational age (AGA) infants (table 1). The distribution of cortisol values among the AGA infants was non-Gaussian and skewed to the right. They had a nearly normal distribution however, when $\log _{10}$ transformed. ${ }^{11}$ The points determined by mean (2 SD) on the logarithmic scale were transformed back to the original units to provide a reference range: 73-562 nmol/1. Taking into account, gestational age, birthweight, and postnatal age as independent variables, and cortisol $\left(\log _{10}\right)$ as the dependent variable in a stepwise multiple regression model, gestational age and birthweight had a significant effect $(\mathrm{p}=0.0041$ and $\mathrm{p}=0.032$, respectively). Birthweight alone was not significantly correlated with cortisol values (regression coefficient $=-0.0001, p=0.363$ ), but after including birthweight in the model, $\mathrm{r}^{2}$ increased from 0.123 to 0.236 . In this model the regression coefficient (standard error) of birth weight was $0.00066(0.00030)$ and the regression coefficient of gestational age was 0.125 (0.041). However, the combination of birthweight and gestational age to predict cortisol values seemed to be cumbersome in clinical practice and birthweight was omitted on grounds of simplicity. The regression coefficient (standard error) of gestation alone was $-0.045(0.020)(p=0.033)$ and the regression equation was $\log ($ cortisol $)=3.5373-0.045 \times$ gestational age. Based on this equation and the residual standard deviation about the regression line, a reference range for each week of gestational was derived (table 2). Again, the points determined by mean (2 SD) on the logarithmic scale were transformed back to the original units to provide a reference range. Furthermore, in AGA infants, no significant differences in cortisol values were found between girls and boys $(p=0.82)$ as well as between those infants whose mothers had or had not received a complete course of prenatal steroids $(\mathrm{p}=0.94)$ (Mann-Whitney U test).

\section{Discussion}

Table 3 summarises the published data on well preterm infants, most of whom were 30 weeks or more of gestational age. ${ }^{121314}$ The definition of "well" varied from a single criterion to very detailed criteria. ${ }^{115}$ In only one study was serum glucose concentration included. ${ }^{14} \mathrm{Fi}-$ nally, none of the studies stipulated the time interval before blood sampling during which the patient remained undisturbed. This is mandatory in intensive care patients, who have a busy programme of nursery care and medical activity. Healthy term infants show an up to 11-fold rise in cortisol half an hour after a painful venepuncture. ${ }^{16}$ The 48 hour interval was based on the observation that cortisol values in term neonates returned to baseline within 48 hours of surgery. ${ }^{17}$ Our strict criteria meant that only $47 \%$ of all eligible infants could be included in the study.

Compared with previously published cortisol values in a more mature population (median cortisol 137, 140, and $104 \mathrm{nmol} / 1$ for

Table 3 Gestational age and criteria of wellbeing on serum cortisol concentrations in preterm infants

\begin{tabular}{|c|c|c|c|}
\hline Reference & Gestational age (weeks) & $n=$ & Criteria of "wellbeing" \\
\hline 1 & $33.5 ; 31-35$ (mean, range) & 13 & Mild or transient respiratory distress \\
\hline 12 & $32.8 ; 28-36$ (mean, range) & 15 & Not seriously ill \\
\hline 13 & 33-36 (range) & 8 & $\begin{array}{l}\text { Healthy mothers, uneventful peri- and postnatal course normal serum } \\
\text { electrolytes, no respiratory distress }\end{array}$ \\
\hline 18 & $28 ; 24-33$ (mean, range) & 25 & $\begin{array}{l}\text { No major congenital malformations, receiving less than } 25 \% \text { inspired } \\
\text { oxygen not requiring assisted ventilation, tolerating full gastric feed }\end{array}$ \\
\hline 14 & $33.5(1.5)$ (mean SD) & 15 & $\begin{array}{l}\mathrm{pH} 7.3-7.4, \mathrm{PaO}_{2} 50-70 \text { Torr, } \mathrm{PaCO}_{2}<55 \text { Torr, serum glucose } 2.5-7.0 \\
\text { mmol/1, serum calcium } \geqslant 2.0 \mathrm{mmol} / 1 \text {, haematocrit }>40 \% \text {, no respiratory } \\
\text { distress }\end{array}$ \\
\hline 15 & $29(1.5)$ (mean SD) & 39 & $\begin{array}{l}\text { No congenital anomalies, no family history of adrenal disorders, no } \\
\text { current major acute illness, had not received inotropes or hormone } \\
\text { treatment within } 48 \text { hours.Infants with mild hyaline membrane disease } \\
\text { and apnoea of prematurity were included. Samples taken within } 48 \\
\text { hours before onset of sepsis were excluded. }\end{array}$ \\
\hline
\end{tabular}


$<30,30$, and 31 weeks postconceptional age, respectively), our values are higher (median cortisol $199 \mathrm{nmol} / \mathrm{l}) .^{15}$ This agrees with our finding of a significantly negative correlation between gestational age and cortisol concentrations and published data. ${ }^{2}$ In this study, the effect of gestational age on cortisol values is more pronounced, if birthweight is included together with gestational age in a multiple regression model, whereas birthweight alone did not have a significant effect on cortisol values. In a recent report cortisol values decreased significantly with advancing postnatal age between 1 and 8 weeks, ${ }^{18}$ but we found only a weak negative correlation between cortisol concentration and postnatal age in the first two weeks of life. This may be explained by the high rate of administration of prenatal steroids in our study group (table 1).

However, the data on adrenal suppression after prenatal administration of corticoids for fetal lung maturation are contradictory. Two groups found postnatal normalisation of suppressed cortisol values within two hours or two days, respectively. ${ }^{19}{ }^{20}$ Others found that serum cortisol concentrations were maximally suppressed by $55 \%$ within the first four to seven days of life ${ }^{182122}$ but not after the first week..$^{1823}$ In our study the cortisol values, which were obtained during the first week, were solely derived from infants whose mothers received prenatal steroids. Only six of 37 (16\%) AGA infants, whose cortisol values were measured on days 7 to 13 , were not under the influence of prenatal steroids. Thus the presented reference range applies to preterm infants after prenatal administrations of betamethasone. This is important, because the generally accepted benefit of prenatal steroids leads to an increasing rate of prenatal administration of steroids in at risk pregnancies. ${ }^{24}$ Among the published findings on serum cortisol, the administration of prenatal steroids was taken into consideration by only one author for the analysis of the data. ${ }^{18}$

Little is known about cortisol concentrations in SGA infants. The concentrations of several glucocorticoids, including cortisol, were lower in term SGA infants than in AGA infants at 12 hours of age, but the cortisol values at 24 hours of age were higher, and after the first day of life no differences were found in cortisol values between term SGA and AGA infants. ${ }^{25}$ These findings suggest a different adrenocortical response in SGA infants and we therefore separated out the SGA infants before further analysis. In this study preterm SGA infants had significantly higher concentrations compared with preterm AGA infants of the same gestational age.

Ten of $47(21 \%)$ of our subjects had cortisol concentrations below $138 \mathrm{nmol} / \mathrm{l}$, the threshold of adrenal insufficiency. ${ }^{26}$ However, they had no clinical signs of adrenal insufficiency. We do not know whether preterm infants under 30 weeks of gestational age with cortisol concentrations < $138 \mathrm{nmol} / 1$ are at greater risk of developing clinical signs of adrenal insufficiency in stressful situations. Our study does not give any information on the function of the hypothalamicpituitary-adrenal axis in these patients.
Although newborn infants lack a circadian rhythm for cortisol, ${ }^{27}$ there is pulsatility of cortisol secretion. ${ }^{28}$ However, only small changes in serum cortisol within ill extremely low birthweight infants were shown by Jett et $a .^{29}$ The standard deviations ranged between 10 and $114 \mathrm{nmol} / \mathrm{l}$. The authors concluded that a single random cortisol measurement adequately reflected the adrenal status of an extremely low birthweight infant. We can therefore fill a gap by supplying a strictly defined reference range for serum cortisol concentrations in well AGA preterm infants with under 30 weeks of gestational age during the first two weeks of life, a period of highest critical morbidity in this population.

We thank Dr J Högel from the Department of Biometry and Clinical Documentation, University of Ulm, for statistical advice.

1 Lee MM, Rajagopalan L, Berg GJ, Moshang TJr. Serum adrenal steroid concentrations in premature infants. 7 Clin Endocrinol Metab 1989;69:1133-6.

2 Scott SM, Watterberg KL. Effect of gestational age, postnatal age, and illness on plasma cortisol concentrations in premature infants. Pediatr Res 1995;37:112-16.

3 Fauser A, Pohlandt F, Bartmann P, Gortner L. Rapid increase of blood pressure in extremely low birth weight infants after a single dose of dexamethasone. Eur $\mathcal{F}$ Pediatr 1993;152:354-6.

4 Bouchier D, Weston P J. Randomised trial of dopamine compared with hydrocortisone for the treatment of hypotensive very low birth weight infants. Arch Dis Child Fetal Neonatal Ed 1997; 76:F174-F8.

5 Gaissmaier RE, Pohlandt F. Single-dose dexamethasone in hypotension in preterm infants. F Pediatr 1999;134:701-5.

6 Ballard JL, Khoury JC, Wedig K, Wang L, Eilers-Walsman BL, Lipp R. New Ballard Score, expanded to include extremely premature infants. F Pediatr 1991;119:417-23.

7 Weller U, Jorch G. Aktuelle Perzentilenkurven für Körpergewicht, Körperlänge und Kopfumfang von Neugeborenen ab 25 SSW. Monatsschr Kinderheilk 1993;141:665-9.

8 Papile LA, Burstein J, Burstein R, Koffler H. Incidence and evolution of subependymal and intraventricular hemorrhage: a study of infants with birth weights less than 1500 grams. F Pediatr 1978;92:529-34.

9 Vecsei P, Penke B, Katzy R, Baek L. Radioimmunological determination of plasma cortisol. Experientia 1972; 28:1104-5.

10 Solberg HE. Approved recommendations (1987) on the theory of reference values Part 5. Statistical treatment of collected reference values. Determination of reference limits. F Clin Chem Clin Biochem 1987;25:645-56.

11 Healy MJR. The disciplining of medical data. Br Med Bull 1968;24:210-14.

12 Thomas S, Murphy JF, Dyas J Ryalls M, Hughes IA. Response to ACTH in the newborn. Arch Dis Child 1986;61:57-60.

13 Doerr HG, Sippell WG, Versmold HT, Bidlingmaier F, Knorr D. Plasma mineralocorticoids, glucocorticoids, and progestins in premature infants: longitudinal study during progestins in premature infants: longitudinal study
the first week of life. Pediatr Res 1988;23:525-9.

14 Economou G, Andronikou S, Challa A, Chovelas V, Lapatsanis PD. Cortisol secretion in stressed babies during neonatal period. Horm Res 1993;40:217-21

15 Saedi SA, Dean H, Dent W, Cronin C. Reference ranges for serum cortisol and 17-hydroxyprogesterone levels in preterm infants. $\mathcal{F}$ Pediatr 1995;126:985-7.

16 Manatagos S, Koulouris A, Vagenakis A. A simple stress test for the evaluation of the hypothalamic-pituitary-adrenal axis during the first 6 months of life. $\mathcal{F}$ Clin Endocrinol Metab 1991;72:214-16

17 Okur $H$, Kücükaydin $M$, Üstal $M$. The endocrine and metabolic response to surgical stress in the neonate. $\mathcal{f}$ Pediatr Surg 1995;30:626-30.

18 Wittekind CA, Arnold JD, Leslie GI, Lutrell B, Jones MP. Longitudinal study of plasma ACTH and cortisol in very low birth weight infants in the first 8 weeks of life. Early Hum Dev 1993;33:191-200.

19 Dörr HG, Versmold HT, Sippell WG, Bidlingmaier F, Knorr D. Antenatal betamethasone therapy: Effects on maternal, fetal, and neonatal mineralocorticoids, glucocorticoids, and progestins. F Pediatr 1986;108:990-3.

20 Kauppila A, Koivisto M, Pukka M, Tuimla R. Umbilical cord and neonatal cortisol levels. Obstetrics Gynecol 1978;52:666-72.

21 Ballard PL, Gluckman PD, Liggins GC, Kaplan SL, Grumbach MM. Steroid and growth hormone levels in premature infants after prenatal betamethasone therapy to prevent respiratory distress syndrome. Pediatr Res 1980;14:122-7. 
22 Parker CR, Atkinson MW, Owen J, Andrews WW. Dynamics of the fetal adrenal, cholesterol, and apolipoprotein B responses to antenatal betamethasone therapy. Am $\mathcal{F}$ Obstet Gynecol 1996; 174:562-5.

23 Ng PC, Wong GW, Lam CW, et al. Pituitary-adrenal response in preterm very low birth weight infants after treatment with antenatal corticosteroids. F Clin Endocrinol Metab 1997;82:3548-552.

24 Crowley PA. Antenatal corticosteroid therapy: A metaanalysis of the randomized trials, 1972 to $1994 . A m ~ f$ Obstet Gynecol 1995; 173:322-35.

25 Doerr HG, Versmold HT, Bidlingmaier F, Sippell WG. Adrenocortical steroids in small-for-gestational-age term infants during the early neonatal period. Pediatr Res 1989;25:115-18.
26 Alkalay AL, Klein AH, Nagel RA, Pomerance JJ. Evaluation of hypothalamic-pituitary-adrenal axis in premature infants treated with dexamethasone. Am f Perinatol 1996; 13:473-7.

27 Vermes I, Dohanics J, Toth G, Pongracz J. Maturation of the circadian rhythm of the adrenocortical functions in human neonates and infants. Horm Res 1980;12:237-44.

28 Metzger DL, Wright NM, Veldhuis JD, Rogol AD, Kerrigan JR. Characterization of pulsatile secretion and clearance of plasma cortisol in premature and term neonates using deconvolution analysis. I Clin Endocrinol Metab 1993;77:458-63.

29 Jett PL, Samuels MH, McDaniel PA, Benda GI, LaFranchi SL, Reynolds JW, Hanna CE. 